ИЗВЕСТИЯ АКАДЕМИИ НАУК ЭСТОНСКОИ ССР. ТОМ 29 ГЕОЛОГИЯ. 1980, № 4

\title{
КЛАССИФИКАЦИЯ ЛИТОЛОГИЧЕСКИХ РАЗНОВИДНОСТЕЙ РАКУШЕЧНЫХ ФОСФОРИТОВ ПРИБАЛТИЙСКОГО ФОСФОРИТОНОСНОГО БАССЕИНА
}

В приглинтовой полосе Ленинградской области и Эстонии оболовые песчаники пакерортского горизонта нижнего ордовика уже около 50 лет представляют собой объект геологических поисков, разведки и эксплуатации, так как образуют уникальные по своему генезису органогенные фосфоритные месторождения, два из которых (Маардуское и Кингисеппское) в настоящее время разрабатываются, а третье (Тоолсе) подготавливается к эксплуатации.

Полезный компонент - фосфорный ангидрид $\left(\mathrm{P}_{2} \mathrm{O}_{5}\right)$ - в количестве $35-37 \%$ входит в состав фосфатных раковин беззамковых брахиопод семейства Obolidae, принадлежащих двум родам - Obolus и Schmidtites.

Качество полезного ископаемого, не затронутого эпигенетическими процессами доломитизации и ожелезнения, зависит от соотношения фосфатного раковинного материала и терригенного кварца; содержание этих двух основных минералогических компонентов изменяется в оболовых песчаниках в широких пределах.

С расширением фронта поисково-разведочных работ, которое имело место в 60-х годах, возникла потребность в разработке такой литологической классификации, которая отражала бы качество полезного ископаемого с точки зрения содержания в нем полезного компонента.

Первая попытка в создании такой классификации была предпринята на месторождении Тоолсе в 1968 г. Однако в ходе дальнейших работ возникла практическая необходимость в выделении значительно большего количества литологических разновидностей оболовых песчаников, чем было предусмотрено этой классификацией. Кроме того, стала очевидной целесообразность замены устаревших, но ставших традиционными, терминов, несущих неправильную смысловую нагрузку, например, термин «оболовый (брахиоподовый) конгломерат» применительно к породам, представляющим собой скопление створок непереотложенных раковин, заменить термином ракушняк.

Результаты исследований последних лет обусловили также при выделении литологических разновидностей оболовых песчаников необходимость не только учитывать содержание в них фосфатов, но и различать последние в соответствии со степенью их сохранности с целью правильного реконструирования обстановки накопления осадков.

Отсутствие в настоящее время детальной литологической классификации оболовых песчаников значительно осложняет взаимопонимание геологов, работающих в различных частях Прибалтийского фосфори- 


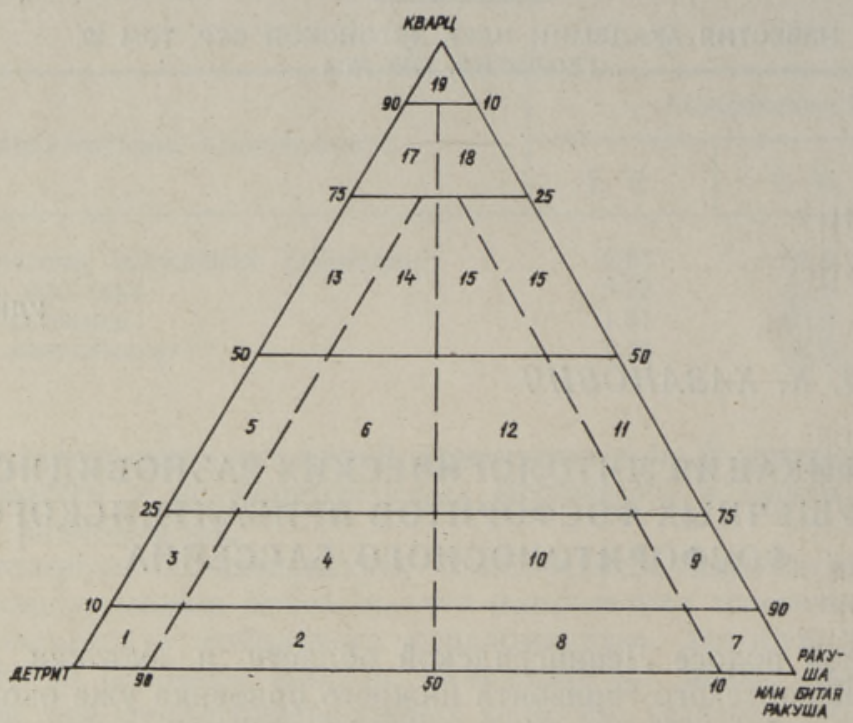

Классификация литологических разновидностей ракушечных фосфоритов тремадока Прибалтийского бассейна. Сплошной линией показаны границы, устанавливаемые точно с помощью химических анализов, пунктиром - границы, устанавливаемые по анализу или по приблизительным визуальным наблюдениям фосфоритного материала.

тоносного бассейна, и является препятствием для реконструкции палеогеографической обстановки формирования ракушечных фосфоритов.

Настоящая классификация имеет своей целью устранить этот недостаток. Она в принципе мало отличается от общеизвестных трехкомпонентных классификаций, применяемых для обломочных (Раукас, 1965) и карбонатных (Единая классификация..., 1965) пород Эстонии и Прибалтики.

В первом случае основой выделения литологических разновидностей является их разный гранулометрический, во втором - компонентный (химический и минеральный) состав.

В основу нижеследующей классификации авторами положены, с одной стороны, разный химико-минеральный состав литологических разновидностей (кварц и фосфатный раковинный минерал) и, с другой, данные о различной степени сохранности фосфатного материала, подразделяемого по этому признаку на детрит и ракушу.

Детрит представляет собой обломочный материал, состоящий из фрагментов фосфатных раковин беззамковых брахиопод, преимущественно оболид. Для определения относительных размеров детрита авторы предлагают использовать следующую его градацию (мм): микроскопический $-<1$; мелкий $-1-3$; средний $-3-5$; крупный $5-10$; очень крупный (грубый) - > 10. Выделяются две генетические разновидности детрита: 1) автохтонный (Палеонтологический словарь, 1965), образовавшийся после отмирания организмов в результате несущественного переноса створок в прибрежной зоне бассейна, отлома и дробления их тонкого переднего края; характеризуется слабой абрадированностью, остроугольностью, мелкими или микроскопическими размерами, малой $(<1$ мм) толщиной, характерен для ракушечной и ракушечно-детритовой генетических разновидностей оболовых песчани- 
Таблица 1

Классификация литологических разновидностей ракушечных фосфоритов тремадока и их распространение на основных месторождениях Прибалтийского бассейна

\begin{tabular}{|c|c|c|c|c|c|c|}
\hline \multirow[b]{2}{*}{ Название } & \multicolumn{3}{|c|}{ Содержание компонентов, \% } & \multicolumn{3}{|c|}{$\begin{array}{c}\text { Наличие на основных } \\
\text { месторождениях }\end{array}$} \\
\hline & Кварц & Детрит & Ракуша & Маарду & $\begin{array}{c}\text { Тоол- } \\
\text { се- } \\
\text { Раквере }\end{array}$ & $\begin{array}{c}\text { Кинги- } \\
\text { сеппп }\end{array}$ \\
\hline Д ет ритит & $<10$ & $>80$ & $<10$ & - & - & - \\
\hline Ракушечный детритит & $<10$ & $50-90$ & $10-50$ & - & - & - \\
\hline Песчанистый детритит & $10-25$ & $65-90$ & $<10$ & - & + & - \\
\hline $\begin{array}{l}\text { Песчанистый ракушечный де- } \\
\text { тритит }\end{array}$ & $10-25$ & $37,5-80$ & $10-45$ & - & - & - \\
\hline Песчаный детритит & $25-50$ & $40-75$ & $<10$ & - & + & - \\
\hline $\begin{array}{l}\text { Песчаный ракушечный детри- } \\
\text { тит }\end{array}$ & $25-50$ & $25-65$ & $10-37,5$ & - & - & - \\
\hline Р акушн як & $<10$ & $<10$ & & - & - & - \\
\hline Детритовый ракушняк & $<10$ & $<50$ & $50-90$ & - & - & - \\
\hline Песчанистый ракушняк & $10-25$ & $<10$ & $65-90$ & + & + & - \\
\hline $\begin{array}{l}\text { Песчанистый детритовый pa- } \\
\text { кушняк }\end{array}$ & $10-25$ & $10-45$ & $37,5-80$ & + & + & - \\
\hline $\begin{array}{l}\text { Песчаный ракушняк } \\
\text { Песчаный детритовый ракуш- }\end{array}$ & $25-50$ & 10 & $40-75$ & + & + & - \\
\hline няк & $25-50$ & $10-37,5$ & $20-65$ & + & + & - \\
\hline $\begin{array}{l}\text { ник } \\
\text { Ракушечно-детритовый }\end{array}$ & $25-50$ & $15-50$ & $<10$ & + & + & + \\
\hline вый песчаник & $25-50$ & $12,5-40$ & $10-25$ & - & - & + \\
\hline $\begin{array}{l}\text { Ракушечный кварцевый песча- } \\
\text { ник }\end{array}$ & $25-50$ & $<10$ & $15-50$ & + & + & - \\
\hline Детрито-ракушечный кварце- & $25-50$ & $10-25$ & $12,5-40$ & + & + & + \\
\hline $\begin{array}{l}\text { Детритистый кварцевый песча- } \\
\text { ник }\end{array}$ & $75-90$ & $5-25$ & $<12,5$ & + & + & + \\
\hline $\begin{array}{l}\text { Ракушистый кварцевый песча- } \\
\text { ник } \\
\text { К в а рце в ы й песчан и к }\end{array}$ & $\begin{array}{c}75-90 \\
>90\end{array}$ & $\begin{array}{c}<12,5 \\
<10\end{array}$ & $\begin{array}{l}5-25 \\
<10\end{array}$ & $\begin{array}{l}+ \\
+\end{array}$ & + & $\overline{+}$ \\
\hline
\end{tabular}

ков; 2) аллохтонный, сформировавшийся в результате размыва и переотложения более древних ракушечных образований; в отличие от первого, как правило, сильно отполирован, имеет блестящую или зеркальную поверхность и закругленные края; элементы строения створок (линии роста, радиальная струйчатость, мускульные отпечатки и др.) в основном полностью уничтожены; такой тип детрита характеризует только отложения суурйыэской (тосненской) пачки, присутствуя в ее детритовых и ракушечно-детритовых разновидностях.

Р акуша представлена целыми створками раковин беззамковых брахиопод или их крупными фрагментами («битая ракуша»). Следует отличать ракушу от крупного детрита раковин Obolus размером более 1 cм. Основным критерием для отличия является степень абрадированности и окатанности створок - очень высокая у детрита и слабо выраженная у ракуши. Необходимо иметь в виду, что ракуша по своим размерам может быть меньше детрита. Так, если целые створки Schmidtites никогда не превышают $2-3$ мм по длине, то детрит раковин Obolus ingricus может достигать 1,5 см, составляя при этом $1 / 3-1 / 4$ часть целой створки.

Подразделение раковинного материала на две группы позволяет 
рассматривать состав ракушечных фосфоритов как трехкомпонентный и дает возможность построить их классификацию по принципу треугольной диаграммы (рисунок и табл. 1).

Составленная диаграмма отражает взаимоотношение в породе трех компонентов: кварца, детрита и ракуши. Привершинные поля треугольника соответствуют «чистым», мономинеральным разновидностям пород, представленных на $80-100 \%$ одним из этих компонентов. Эти разновидности следующие:

1) кварцевый песчаник (алевролит) с детритом или ракушей: содержание фосфатов в породе менее $10 \% \quad\left(<3-4 \% \quad \mathrm{P}_{2} \mathrm{O}_{5}\right)$, вся остальная часть представлена кварцем и другими терригенными минералами; в соответствии с существующими кондициями при подсчете запасов ракушечных фосфоритов эти разновидности пород промышленного значения не имеют;

2) оболовый ракушняк (ракушечник) представляет собой породу, состоящую на $80-100 \%$ из целых створок раковин Obolus и Schmidtites или их крупных фрагментов, с примесью раздробленного раковинного материала - детрита (до 10\%) и зерен кварца (до 10\%);

3) порода, в которой содержание детрита раковин составляет более $80 \%$; ввиду отсутствия в существующей геологической терминологии названия, которое отражало бы состав этой породы, авторы предлагают использовать новый термин - детритит.

Кроме рассмотренных «чистых» разновидностей ракушечных фосфоритов, согласно предлагаемой классификации, выделяется 16 промежуточных по составу пород, обладающих различными количественными соотношениями кварца, фосфатного детрита и фосфатной ракуши (табл. 1).

Все разновидности детритита и ракушняка содержат фосфатный материал более $50 \%$ от количества породы. Линия на диаграмме (см. рисунок), соответствующая значению $50 \%$ кварца, является разграничивающей между породами преимущественно фосфатного состава детрититами и ракушняками, с одной стороны, и песчаниками, с другой.

При анализе таблицы и треугольной диаграммы необходимо отметить следующее.

1. Значения содержаний кварца и суммы фосфатов могут быть получены с большой точностью с помощью химических анализов и при их пересчете на минеральный состав (табл. 2), что оправдывает дробность градации литологических разновидностей по направлению кварцфосфаты.

2. Точное соотношение в породе ракуши и детрита, обладающих одинаковым минеральным и химическим составом, может быть установлено только при помощи минералогического анализа под бинокуляром, в процессе которого раковинный материал должен быть отсортирован на две части в зависимости от степени его окатанности и фрагментарности. Учитывая трудоемкость этой операции и практическую невозможность ее применения в больших объемах, предусматривается, что определение соотношения этих компонентов в породе производится визуально в процессе макроскопического описания. Естественно, что низкая точность таких определений не позволяет выделить на диаграмме промежуточные разности детрититов и ракушняков с таким же дробным подразделением, как в направлении кварц-фосфаты. В связи с этим на диаграмме в каждом из трех рядов детритит-ракушняк и в 
Таблица 2

Выделение основных литологических разновидностей ракушечных фосфоритов по химическому составу

\begin{tabular}{|c|c|c|c|c|}
\hline \multirow{2}{*}{\multicolumn{2}{|c|}{ Наименование разновидностей }} & \multicolumn{3}{|c|}{ Содержание, \% } \\
\hline & & $\begin{array}{c}\text { Фосфатный } \\
\text { раковинный } \\
\text { материал }\end{array}$ & $\begin{array}{l}\text { Кварц } \\
\left(\mathrm{SiO}_{2}\right)\end{array}$ & $\mathrm{P}_{2} \mathrm{O}_{5}$ \\
\hline \multirow{3}{*}{ 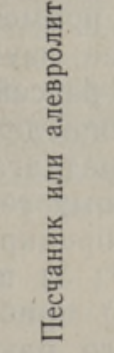 } & Кварцевый & $<10$ & $>90$ & $<4$ \\
\hline & $\begin{array}{l}\text { Детритистый или раку- } \\
\text { шистый }\end{array}$ & $10-25$ & $75-90$ & $4-9$ \\
\hline & $\begin{array}{l}\text { Детритовый или раку- } \\
\text { шечный }\end{array}$ & $25-50$ & $50-75$ & $9-18$ \\
\hline \multirow{2}{*}{ 点总 } & Песчаный & $50-75$ & $25-50$ & $18-27$ \\
\hline & Песчанистый & $75-90$ & $10-25$ & $27-32$ \\
\hline \multicolumn{2}{|c|}{ Детритит или ракушняк } & $>90$ & $<10$ & $>32$ \\
\hline
\end{tabular}

ряду детритовый песчаник-ракушечный песчаник выделяются только две промежуточные разности, содержание фосфатных компонентов в которых изменяется в широких пределах (от 10 до 50\%). Для правильного определения породы, таким образом, нет необходимости в количественном выражении содержания тех или иных фосфатов, а достаточно указание на то, какие их разновидности присутствуют в бо́льших или меньших количествах.

3. Определение количественных соотношений в породе аллохтонного и автохтонного детрита также возможно только с помощью специальных минералогических исследований под бинокуляром, что в условиях большого объема опробования является трудоемким. В связи с этим предлагаемой классификацией предусмотрено, что генезис детрита не имеет значения для определения состава породы. Однако нужно иметь в виду, что практически в ряду детритит-детритовый песчаник детрит представлен преимущественно аллохтонными разностями, а в ряду ракушняк-ракушистый песчаник - автохтонными. В промежуточных по составу породах он представлен разностями того и другого генезиса.

Опыт практического применения данной классификации по новым материалам основных разведанных месторождений Маарду, Тоолсе и Кингисепп (табл. 1) показывает, что не все рубрики классификации представлены реальным материалом в равном количестве. Видно, что полностью отсутствуют представители чистых фосфатных пород, содержащих кварц лишь до $10 \%$. Такое явление вполне нормально, учитывая накопление фосфатных створок раковин брахиопод на фоне общей терригенной седиментации. Важным является также закономерность, 
что широко представлены породы, в которых преобладает ракуша, а детритовые породы характерны чаще всего для района ТоолсеРаквере. Разумеется, эти данные являются лишь предварительными и ориентировочными и они не ограничивают применение классификации в целом. Наоборот, предлагаемая классификация применима и для научных целей. Так, детальное изучение литологического состава этих пород, выяснение закономерностей формирования фосфоритовых залежей невозможно без применения комплексного, палеоэколого-литологического метода исследований (Геккер, 1957). Предлагаемая нами литологическая классификация может найти практическое применение только при условии использования этого метода в процессе изучения фосфоритных ракушечных месторождений Прибалтийского бассейна.

Палеоэкологические наблюдения, необходимые для определения литологического состава песчаников в соответствии с предлагаемой классификацией, достатбчно просты, вполне доступны любому геологу и заключаются в определении: 1) степени сохранности и абрадированности раковин; 2) их родовой и видовой принадлежности *; 3) преобладающих размеров детрита или фрагментов створок; 4) приблизительного соотношения неабрадированного и раздробленного раковинного материала.

Эти наблюдения должны способствовать более точному определению литологического состава фосфоритоносных пород и их официальной принадлежности, что самым тесным образом связано с выяснением условий формирования богатых фосфоритовых залежей и закономерностей их площадного распространения.

Применение рассмотренной литологической классификации ракушечных фосфоритов по их первичному вещественному составу, вероятно, возможно не только в пределах Прибалтийского бассейна, но и в других районах их распространения, например, на территории Иркутского амфитеатра. Не исключается возможность использования этой классификации и в случае других органогенно-терригенных образований независимо от минерального состава раковинного материала.

* Породообразующее значение имеют только 3 легкодиагносцируемых вида оболид Obolus ingricus, O. apollinis и Schmidtites celatus.

\section{Л И Т Е Р А Т Р Р А}

Ге к ке р Р. Ф. Введение в палеоэкологию. М., 1957.

Единая классификация и легенда карбонатных пород. Таллин, 1965.

Палеонтологический словарь. M,, 1965.

Р а укас А. Гранулометрическая классификация обломочных пород. - В кн.: Литология и стратиграфия четвертичных отложений Эстонин. Таллин, 1965, $133-148$.

Государственный научно-исследовательский институт горно-химического сырья (ГНГХС) 


\section{BALTI FOSFORIIDIBASSEINI OOBOLUSFOSFORIIDI LITOLOOGILISTE ERIMITE KLASSIFIKATSIOON}

Artiklis on esitatud Eestis ja Leningradi oblastis leviva alamordoviitsiumi pakerordi lademe oobolusfosforiidi klassifikatsioon. Selle aluseks on kolmekomponendiline süsteem: brahhiopoodikojad-detriit-kvarts. Graafiliselt on klassifikatsioon esitatud kolmnurkdiagrammina, milles oobolusfosforiit on jaotatud 19 erimiks. Diagrammi kasutamist raskendab mõneti asjaolu, et fosfaadi jaotust terveteks kodadeks ning detriidiks saab määrata ainult detailse mineraloogilise analüüsiga, mis on väga töömahukas ja aeganõudev. Seepärast on soovitatud praktiliste tööde puhul kasutada klassifikatsiooni lihtsustatud varianti, milles oobolusfosforiit on jaotatud 6 erimiks. Selleks on kivimis määratud fosfaadi koguhulk ja see jaotatud visuaalse hinnangu järgi autohtoonseks ja allohtoonseks komponendiks.

Klassifikatsioon on kasutatav kõikjal, kus levivad samalaadsed kivimid kui Balti fosforiidibasseinis.

\section{R. RAUDSEP, K. HAZANOVITCH}

\section{CLASSIFICATION OF LITHOLOGICAL VARIETIES OF OBOLUS PHOSPHORITE OF THE BALTIC PHOSPHORITE BASIN}

The authors present a classification of the obolus phosphorite of the Lower Ordovician Pakerort Stage in Estonia and Leningrad Region. It is based on a three-component system: brachiopod valves-detrite-quartz. Graphically, the classification is represented as a triangular diagramme in which obolus phosphorite is divided into 19 varieties. The application of the diagramme is somewhat complicated by the fact that a division of the phosphate into intact valves and detrite can be determined only by a detailed mineralogical analysis, which is a very cumbersome and time-consuming task. For that reason, it is recommended, for practical purposes, to use a simplified variant of the classification, according to which obolus phosphorite is divided into 6 varieties. For that purpose, the total content of the phosphite in the rock is determined, and divided by visual assessment into the autochthonous and allochthonous component.

The classification can be used in all deposits of the same kind of rocks as those occurring in the Baltic phosphorite basin. 